\title{
ICF1002960R
}

\section{Corrosion Fatigue of High Pressure Die Cast Magnesium Alloys}

\author{
W. G. Ferguson ${ }^{1}, \mathrm{Wu} \mathrm{Liu}^{1}$ and John MacCulloch ${ }^{2}$ \\ ${ }^{1}$ The Chemical \& Materials Engineering Department, The University of Auckland, \\ Private Bag 92019, Auckland, New Zealand \\ E-mail: wg.ferguson@auckland.ac.nz \\ ${ }^{2}$ Magnesium Technology Ltd, \\ 137 Captain Springs Rd, Onehunga, Auckland, New Zealand
}

\begin{abstract}
:
To determine the effect of a coating on fatigue strength, three point bending fatigue tests of coated and un-coated specimens of AM50 and AZ91D magnesium high pressure die castings were made and S-N curves determined. Environments adopted were air, tap water and natural seawater. A difference in corrosion fatigue performance has been found, between AZ91D and AM50 and for both alloys performance in air was superior to both water environments. AZ91D has better corrosion fatigue resistance in tap water than in seawater; conversely, AM50 has better corrosion fatigue resistance in seawater than tap water. The results showed that the fatigue life was not reduced in these water environments for coated specimens, as the coating usually provided sufficient protection from corrosion
\end{abstract}

Key words: magnesium, high pressure die casting, fatigue, corrosion fatigue, coating

\section{INTRODUCTION}

Magnesium is the lightest of the commercial metallic construction materials. Die cast magnesium parts are rapidly replacing steel and aluminium structural components in automotive applications, as design engineers seek to reduce assembly costs, raise fuel efficiency, and improve safety. In addition to an excellent strength-to-weight ratio, magnesium die-castings offer good fatigue strength, high impact and dent resistance, good corrosion resistance, thermal and electrical conductivity. Corrosion resistance of magnesium alloys today is a less serious problem because of better control of alloying element contents.

The magnesium alloys used for this project are AZ91D and AM50 high-pressure die casting alloys. AZ91D die-castings have high values of fatigue strength and are among the most corrosion resistant of the magnesium alloys [1]. Many structural applications require an appreciable amount of energy absorption during service. Magnesium alloys having lower aluminium contents, such as AM50 have been found to be more ductile, especially during impact situations. AM50 alloy has been employed to fabricate prototype wheels for cars [2]. It is now possible to make large complex castings such as integral instrument panel/cross beam members for vehicles using AM60 [3] and high integrity crash sensitive components such as steering wheel frames in AM50 [4].

Corrosion is still a problem for these magnesium alloys for most applications. Magnesium alloys may be used under wet or chemical environments, thus a coating should be applied to improve corrosion resistance. There are two main reasons for the poor corrosion resistance of many magnesium alloys [5-7]. Firstly, there is internal galvanic corrosion caused by second phases or impurities. Secondly, the quasi-passive hydroxide film on magnesium is much less stable than the truly passive film which can form on metals such as stainless steels. This quasi-passivity causes poor pitting resistance in magnesium and its alloys. 
A recently published review of the fatigue behaviour of magnesium alloys shows there are very few fatigue data available to the practising engineer [8]. Specifically, there is a lack of information concerning low cycle fatigue, cyclic stress-strain, mean strain-stress and fatigue crack growth behaviour. The literature on magnesium alloy fatigue behaviour is incomplete, covering only specific topics for some magnesium alloys. Examples of stress-life (S-N) curves are found for some alloys.

In many cases, metallic corrosion is governed by the characteristics of its surface films. For magnesium, the nature of the film is not well understood [9]. Hence, corrosion prevention is very important and essential for commercial applications. There are several ways to protect magnesium and its alloys from corrosion [10]: high purity alloys; new alloys; surface modification; protective films and coatings. In this project, an anodised coating is used to determine coating effects on corrosion fatigue performance for AZ91D and AM50.

Normally, corrosion fatigue is very sensitive to testing frequency, especially for structural steels. For magnesium alloys, it has been noted that: "frequency dependence of corrosion fatigue strength showed that the influence of a corrosion environment decreased with increasing frequency" [11]. However, no data showing the influence of frequency on fatigue performance of magnesium has been cited. Work on the effect of test frequency is in progress.

\section{TEST MATERIAL AND ENVIRONMENT}

Test specimens were $10 \mathrm{~mm} \times 10 \mathrm{~mm}$ cross-section bars, $50 \mathrm{~mm}$ long with smooth die cast surfaces. These specimens, which were die cast to shape without heat treatment, allow three point bend fatigue tests to be conducted with a $40 \mathrm{~mm}$ span. Bending fatigue tests were carried out with an MTS810 using constant load amplitude control, R-ratio of 0.25 and frequency of either 30 or 40 Hz. Tests were stopped when they reached $7.0 \mathrm{E}+06$ cycles and at least three tests have been conducted for each test condition. Tests were performed in air, tap water and natural seawater. The natural seawater was taken from a local Auckland beach and the tap water from a tap in the MTS laboratory. Coated specimens were made to investigate the fatigue performance in seawater of magnesium alloys with or without coating. $5 \mu \mathrm{m}$ and $25 \mu \mathrm{m}$ thick coatings, and $5 \mu \mathrm{m}$ and $25 \mu \mathrm{m}$ thick organically sealed coatings were prepared at the site of Magnesium Technology Licensing Limited, who supplied a new anodising process, 'Anomag'.

\section{RESULTS AND DISCUSSION}

\section{Environmental Influence on Fatigue Performance.}

The fatigue performance of un-coated AM50 die cast alloy at various stress levels in air, tap water and natural seawater environments is shown in Figure 1. Maximum stress is plotted against the logarithm of the number of cycles to failure. The points with arrows are identified as "did not fail" at a certain stress level and number of cycles (tests were stopped when they reached 7.0E +06 cycles).

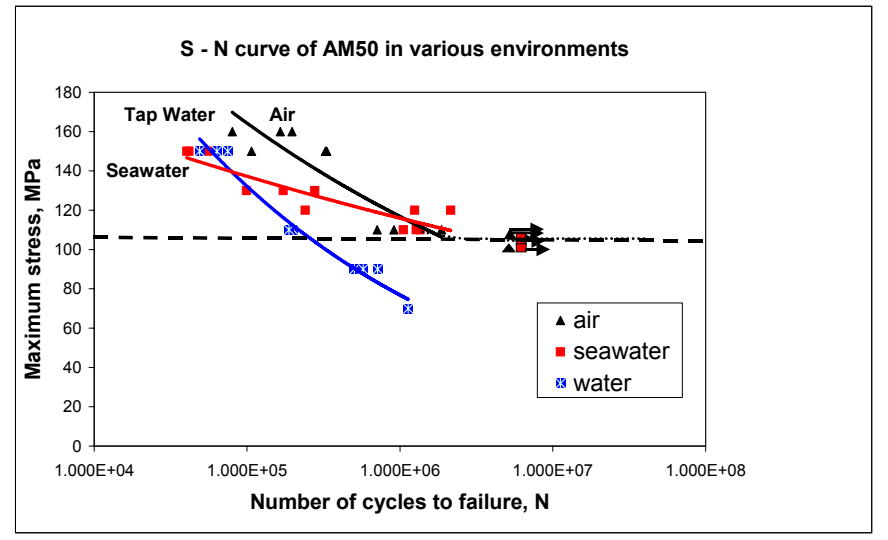


At high maximum stress, AM50 had best fatigue life in an air environment, with the effects of tap water and seawater environments being the same. For low maximum stress the curves for air and seawater drop slowly to an endurance limit of about $105 \mathrm{MPa}$. All specimens, tested in air and seawater at a maximum stress of $105 \mathrm{MPa}$, did not fail after $7.0 \mathrm{E}+6$ cycles. However, the fatigue performance in tap water showed significantly different behaviour; the curve continues to decrease and shows no fatigue limit at $70 \mathrm{MPa}$, where a specimen failed after $1.0 \mathrm{E}+6$ cycles. It would appear that S-N curves have a 'knee' in air and seawater environments, but not in a tap water. These results are not consistent with our general knowledge of corrosion fatigue behaviour of magnesium alloys, in that it has been noted: "Sea water has a greater corrosive effect than tap water because chloride ions react with and remove the protective films from the surfaces of magnesium alloys" [12]. Eliezers et.al. [13] report similar behaviour for $5 \% \mathrm{NaCl}$ solution and water environments where life depends on aluminium content with about $4 \% \mathrm{Al}$ giving least life in a water environment.

It would appear that tap water is enhancing the fatigue process as expected with corrosion fatigue; but that seawater, which is assumed to be more corrosive, has a smaller effect on fatigue performance. The un-coated AM50 high pressure die castings have excellent corrosion fatigue behaviour in a seawater environment. A possible reason for the abnormal behaviour is that the more aggressive environment reduces crack initiation by decreasing or reducing the stress concentration at crack initiation sites, corrosion products may also cause crack blunting and reduce crack growth.

The fatigue performance of AZ91D die cast alloy at various stress levels in air, tap water and natural seawater environments is shown in Figure 2. It can be seen that the best fatigue life for AZ91D is in an air environment, while the effects of tap water and seawater environments within the fatigue scatter give similar but reduced performance. The S-N curve for air decreases sharply to a "knee" between 115MPa to 110Mpa being the fatigue endurance limit of AZ91D in an air. The fatigue performance in tap water and seawater is different to that in air. The fatigue resistance in tap water and seawater is significantly decreased, especially at low stress levels. The S-N curve in a tap water environment is slightly above the S-N curve in a seawater environment, which shows the slightly better fatigue resistance is in tap water compared with that in seawater. Both curves continue to decrease and possibly will not show a fatigue limit.

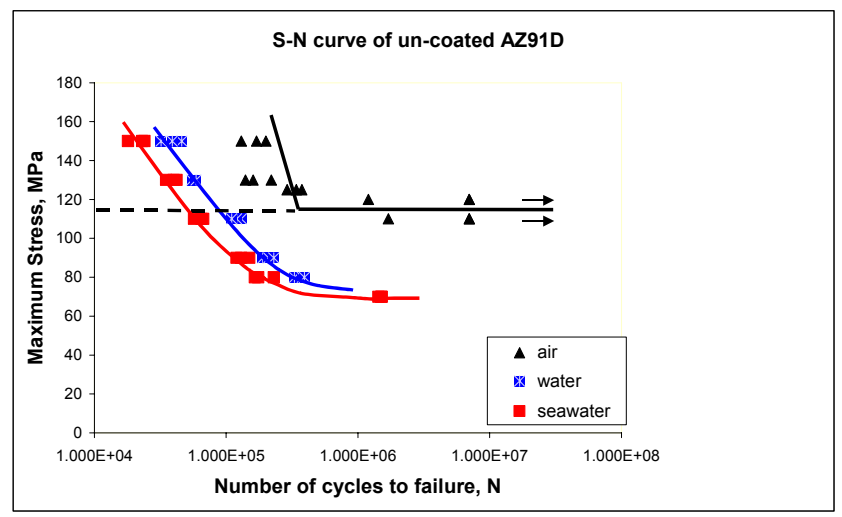

Fig.2 S-N curves of un-coated AZ91D (30Hz, $R=0.25$, bending fatigue)

Generally, the corrosion fatigue resistance for AM50 is always better than that for AZ91D in both tap water and seawater. The comparison of mean fatigue lives for these two alloys in both tap water and seawater are shown in figures 3 and 4. This result supports Eliezer et.al's work [13], in 
which it was found that the less the aluminium content in magnesium alloys, the better the corrosion fatigue resistance. Eliezer et.al [14] also report that the sensitivity of AZ91D alloy to corrosion fatigue is higher than that of AM50 alloy when tested in $3.5 \% \mathrm{NaCl}$ solution.

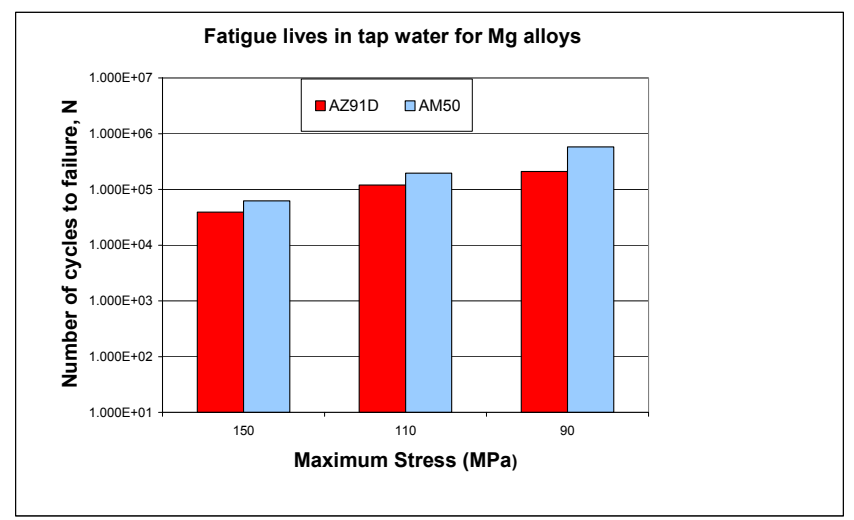

Fig.3 Fatigue lives in tap water for un-coated AM50 and AZ91D

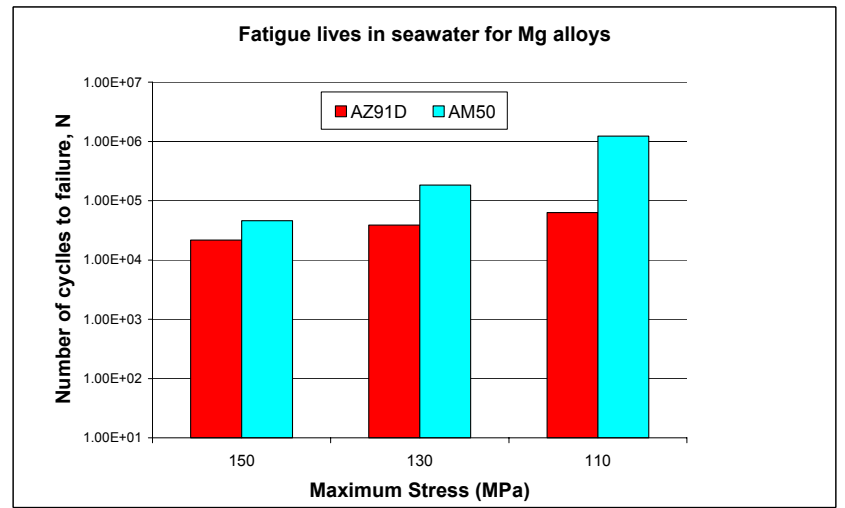

Fig.4 Fatigue lives in seawater for un-coated AM50 and AZ91D

\section{Coating Influence on Corrosion Fatigue Behaviour}

A special coating ('Anomag' anodising) has been used on AM50 and AZ91D die cast specimens to determine the influence of surface protection on fatigue performance in a seawater environment. The results of fatigue tests in seawater for coated and un-coated AZ91D and AM50 show that the special coating and coating \& sealing ('Anomag') do not decrease the fatigue properties in the seawater environment (see figures $5 \& 6$ ). It has been noted that magnesium coating treatments, which are applied for corrosion protection, usually decrease the fatigue and corrosion fatigue resistance of materials in air, but not in seawater[15].

As the coating affects the number of cycles required to start a crack, the effect of coating on the total fatigue life should decrease with increasing stress amplitude. On the basis of this consideration, the most reliable estimate of the effect of the coating should be obtained from tests at low stress levels where the number of cycles to initiate cracking is large in comparison with the crack growth portion of the tests [16].

It can be seen from figure 5 that un-coated specimens in air have about the same fatigue resistance as coated specimens in seawater. The fatigue life of un-coated specimens in air is slightly higher than for the coated specimens at higher stress levels but at lower stress levels, there seems to be little difference in the fatigue life for all specimens. Considering the usual scatter of fatigue results, there is little difference between the S-N curves for un-coated and coated AM50 in seawater, at all stress levels. As un-coated AM50 has excellent corrosion fatigue resistance in seawater, the influence of a thin coating or sealing treatment should not show much improvement in fatigue performance. 


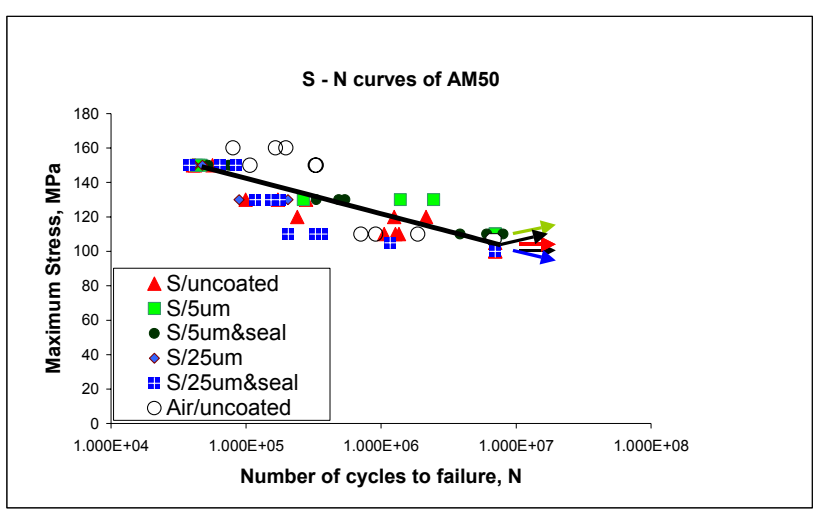

Fig. 5 S-N curves of coated and un-coated AM50 in seawater ( $40 H z, R=0.25)$

For AZ91D, it can be seen the coating treatment increases the corrosion fatigue performance, as the $\mathrm{S}-\mathrm{N}$ data for coated specimens in seawater is always above the curve for un-coated specimens, but below the S-N curve of un-coated specimens in air (see figure 6). It can also be seen that the effect of coating increases with decreasing stress levels. There is little difference in fatigue life for coated and un-coated specimens in seawater at high stress levels, and the difference gets greater when the stress level decreases. As the stress decreases the life for $5 \& 25 \mu \mathrm{m}$ coated specimens approaches the air curve and then falls as the stress drops further. Similar behaviour has been reported by Beck [12] for tap water.

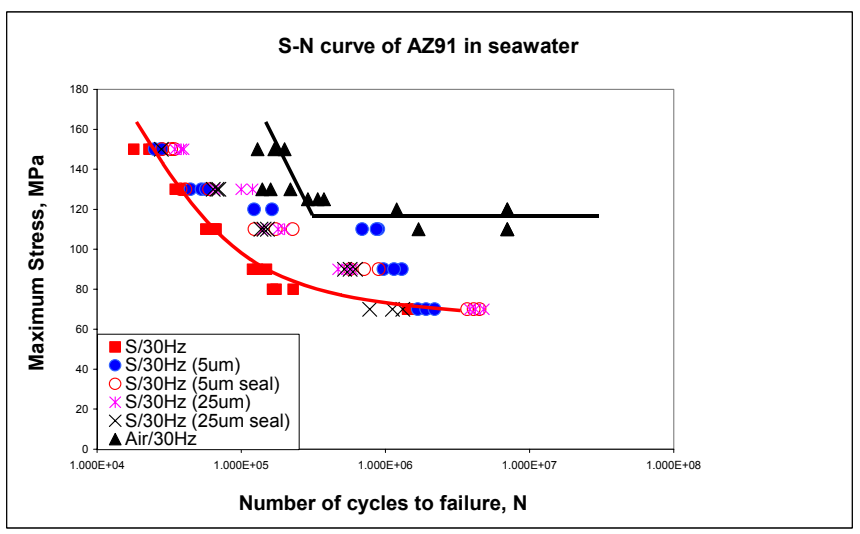

Fig.6 S-N curves of coated and un-coated AZ91D in seawater $(30 \mathrm{~Hz}, \mathrm{R}=0.25)$

It can be seen that the effect of coating or coating $\&$ sealing on corrosion fatigue performance in seawater is greater for AZ91D than for AM50. A possible reason is that the fatigue resistance for un-coated AM50 is much higher than that for un-coated AZ91D in a seawater environment.

\section{CONCLUSIONS}

- The endurance limits in bending for un-coated AM50 and AZ91D die cast alloys are about $105 \mathrm{MPa}$ and $115 \mathrm{MPa}$ (maximum stress), respectively.

- AM50 and AZ91D have different corrosion fatigue performances. There seems to no endurance limit for AM50 in tap water and for AZ91D in both tap water and seawater. Uncoated AM50 has a better corrosion fatigue resistance than AZ91D in water(tap \& salt) environments but not in air.

- AM50 has excellent corrosion fatigue resistance in a seawater environment. The endurance limit $\left(7 \times 10^{6}\right)$ in seawater is about $105 \mathrm{MPa}$ (maximum stress), which is higher than that in tap water, but equal to that in air. 
- There are no negative effects of coating and coating \& sealing on fatigue performance in seawater for AM50, and a slight improvement in the performance for AZ91D.

\section{REFERENCES}

1. Magnesium Casting Alloys, SAE J465 JAN89, SAE standard 10.113.

2. F.H. Froes, The Science, Technology and Applications of Magnesium, JOM, Sept.,1998, 30-32.

3. K. Peete and L. Winkler, Paper 930421, Int. SAE Congress, Detroit, March, 1993.

4. W. Hirth, Mg Alloys and their Applications, DGM Conf., Germany, 1992, 375-379.

5. G.L. Makar, J. Electrochem. Soc., 137(2), 1990, 414-421

6. E.F. Emley, Principles of Magnesium Technology, Chapter XX, Pergamon Press, 1966

7. L.J. Polmear, Light Alloys; Metallurgy of the Light Metals, $2^{\text {nd }}$ Edition, Edward Arnold, 1989

8. V.V. Ogarevic and R.I. Stephens, Fatigue of Magnesium Alloys, Ann. Rev. Mater.Sci.,1990, 20

9. Mechanical Testing, Metals Handbook, ASM International, $9^{\text {th }}$ Edition, $\underline{\text { Vol } 8}, 1985$

10. G.L. Makar and J. Kruger, International Materials Reviews, 38930, 1993, 138-153

11. Failure Analysis and Prevention, Metals Handbook, ASM International, $9^{\text {th }}$ Ed., Vol 11, 1986

12. A. Beck, The Technology of Magnesium and its Alloy, Hughes and Co, London, 1943

13. E.M Eliezer, E.Gutman, E. Abramov and E. Aghion, Corrosion Reviews, Vol. 16, No1-2, 1998

14. E. M. Gutman, Ya. Unigovski, A. Eliezer, E. Abramov and L. Riber, Light Metals Age, December, 2000, 14 - 20

15. H. T. Sumsion, J. Spacecr. Rocket, 5(6), 1968, 700-704.

16. J.A. Bennett, Proc. Am. Soc. Test. Mater., 55, 1955, 1015-19. 